\title{
LIBERDADE E COAÇÃO NO DIREITO DE KANT
}

Celso de Moraes Pinheiro*

RESUMO - Kant divide a filosofia moral em duas partes: Ética e Teoria da Justiça. Cada uma é composta de diferentes descrições de deveres e direitos. A Ética contém deveres e direitos internos, voluntários e não-coercitivos. A Teoria da Justiça contém deveres e direitos externos e coercitivos. Os dois tipos de deveres e direitos são definidos em sua relação um com o outro. O que distingue os deveres éticos, ou deveres de virtude, dos deveres jurídicos, é que a compulsão externa para o dever jurídico é moralmente possível, enquanto o dever de virtude é baseado na livre coerção própria. Assim, a finalidade deste artigo é pesquisar a noção de dever, e a relação entre dever, liberdade e coação.

PALAVRAS-CHAVE - Dever. Liberdade e coação.
ABSTRACT - Kant divides moral philosophy into two parts: Ethics and the theory of justice. Each is composed of different sets of duties and rights. Ethics contains internal, voluntary, and unenforceable duties and rights. The theory of justice contains external, enforceable, and coercive duties and rights. Both types of duties and rights are defined in relation to each other, and therefore can be understood only in relation to each other. What distinguishes ethical duties or duties of virtue from juridical ones is that external compulsion to a juridical duty is morally possible, whereas a duty of virtue is based on free selfconstraint. So, the main purpose of this article is to research the notion of duty, and the relationship between duty, freedom and coercion. KEY WORDS - Duty. freedom and coercion.

As análises contemporâneas acerca do conceito de direito e sua relação com a liberdade, sobretudo em autores como Habermas, Rawls e Höffe, mostram a importância fundamental da compreensão do tratamento dado a esses conceitos por Kant. Não raras vezes, encontramos nos autores acima citados, alusão direta a Kant. A argumentação kantiana é, por vezes, reescrita, de modo a corroborar e assentar em princípios claramente fundados tais conceitos. Partindo desses pressupostos, e a fim de criar subsídios coerentes e corretos para possíveis análises sobre o direito, a liberdade e a coação em autores contemporâneos, pressupomos necessário e esclarecedor um estudo sobre o fundamento conceitual elaborado por Kant.

Desse modo, podemos inicialmente dizer que, nas análises sobre o direito, Kant considera como fundamentais dois conceitos: liberdade e coação. Aparentemente contraditórios, vemos que ambos encontram-se como fundamento de pos-

Professor da Universidade Federal do Paraná (DTPEN).

\begin{tabular}{|l|l|l|l|l|l|}
\hline VERITAS & Porto Alegre & v. 52 & n. 1 & Março 2007 & p. 15-24 \\
\hline
\end{tabular}


sibilidade do direito em Kant. A principal característica do direito, segundo Kant, é a de indicar a coação como aquela que se impõe ao meu agir, impedindo que faça obstáculo à liberdade do outro. Em outros termos, a igualdade suposta no direito implica um obstáculo ao obstáculo, pois, para que, ao mesmo tempo que sou coagido, possa também coagir, é necessária uma reciprocidade eqüitativa. A questão básica que se impõe, a partir dessas considerações, pergunta como o direito, enquanto direito à liberdade, pode ser pensado sem contradições com a coação? Fundar o direito na liberdade e na coação é mostrar sua reciprocidade com o conceito de justiça, uma vez que a liberdade e a coação nos indicam o papel do dever nessa relação. Toda lei traz um ato coercitivo consigo, esteja ele designado como imperativo ou como coação. O que importa é que não há lei sem dever, do mesmo modo que não há justiça sem dever. O conceito de dever é ponto comum entre os âmbitos da moralidade e da legalidade. E, quando analisamos o conceito de dever em Kant, percebemos que, através dele, podemos vislumbrar uma aproximação entre os âmbitos da moralidade e da legalidade. O dever moral, trazido à luz pelo imperativo categórico, é representado, no âmbito da legalidade, pelo direito e pela justiça. Assim, poderíamos supor que, através do dever, podese vislumbrar a relação entre liberdade e coação pretendida por Kant.

A fim de melhor esclarecer a importância do dever para a determinação de uma possível aproximação entre os campos da moral e da legalidade, devemos estabelecer o que podemos compreender pela expressão "justiça" em Kant. Kant busca a determinação do conceito de justiça, de maneira mais exata e cuidadosa, em dois textos, a saber, a Metafísica dos Costumes e Teoria e Prática. Nestes, podemos encontrar duas passagens que se aproximam e se tornaram clássicas na determinação do conceito de justiça, a saber, no primeiro está assim descrito: "Aquilo que é direito (recht), segundo leis externas, se chama justo (gerecht justum), o que não é, injusto (ungerecht - injustum). Em Teoria e Prática, Kant escreve: "É injusto, isto é, se opõe ao dever". Não é difícil, desde um primeiro momento, percebermos nesta segunda passagem, uma forte ligação entre dever e justiça, visto que aquilo que é oposto ao dever é injusto. Ora, parece óbvio, portanto, que o justo mantém uma aproximação com o conceito de dever. Além disso, devemos estar atentos para o fato de que, se analisarmos com mais atenção as aludidas citações, veremos que o termo justiça, em alemão Recht, possui a mesma tradução que direito, também Recht. A partir dessas considerações, poderíamos ler assim a segunda passagem: "É contrário ao direito, isto é, se opõe ao dever". Ora, com isso podemos perceber que essa segunda passagem confirma a intenção da primeira, ou seja, confirma que aquilo que é direito é justo, já que ser oposto ao direito é, ao mesmo tempo, ser oposto ao dever.

Dessa forma, será possível pressupor que, por meio do conceito de dever, os âmbitos do direito e da moral se aproximam. Isso torna-se possível porque, a partir da relação deles com o dever, vislumbramos algo em comum, ou seja, o dever aparece como ponto comum nos campos da moral e do direito. Podemos, então, 
perguntar pelo que seja esse dever, que interpenetra os campos do direito e da moral. Se recorrermos à Divisão da Doutrina do Direito, veremos que Kant vai levar a cabo, em primeiro lugar, uma divisão geral dos deveres do direito, baseada naquela apresentada por Ulpiano em Corpus Iuris Civilis. ${ }^{1}$ Entretanto, Kant procura, segundo suas próprias palavras, dar um sentido, não dado por Ulpiano às suas formulações. A primeira máxima, honeste vive, é definida por Kant como honestidade jurídica. A segunda formulação de Ulpiano, neminem laedere, que ordena que não se faça mal a ninguém, define, segundo Kant, um dever de direito externo, que exprime a lex juidica. A terceira e última formulação,i- suum cuique tribuere, corresponde, de acordo com Kant, ao dever que o homem tem de entrar numa sociedade que rege a lex justitiae. Essa lei de justiça é comparável, em sua forma, à decisão judiciária de um tribunal, onde se fazem derivar os deveres externos, do princípio dos deveres internos ${ }^{2}$. Com essa divisão, Kant afirma que as "três fórmulas clássicas são princípios da divisão do sistema dos deveres jurídicos em deveres internos, externos, e naqueles que contêm a derivação dos últimos, a partir do princípio dos primeiros, por subsunção".

Na Crítica da Razão Prática, Kant apresenta uma análise do conceito de dever que nos faz ver sua relação com os distintos âmbitos da moralidade e da legalidade. Diz Kant:

Portanto o conceito de dever exige na ação, objetivamente, concordância com a lei, mas na sua máxima, subjetivamente, respeito pela lei, como o único modo de determinação da vontade pela lei. E disso depende a diferença entre a consciência de ter agido conformemente ao dever e a de ter agido por dever, isto é, por respeito à lei, cuja primeira forma de consciência (a legalidade) é possível, mesmo que apenas as inclinações tivessem sido os fundamentos determinantes da vontade, enquanto a segunda forma (a moralidade), o valor moral, tem que ser posta unicamente em que a ação ocorra por dever, isto é, simplesmente por causa da lei. ${ }^{4}$

A consciência da ação, portanto, é fundamental para a determinação de qual tipo de dever está em jogo. Vemos que Kant afirma que, quando a ação ocorre conforme o dever, então a ação se encontra no âmbito da legalidade, mas, quando a ação é por dever, então estamos no âmbito da moralidade. Com isso, mesmo uma boa ação, cumprida por interesse, por prazer, ou por qualquer outra intenção, que não a pura ação por dever, não possui qualquer valor moral. O princípio do querer, a máxima da ação é a regra de virtude pela qual a ação é cumprida. E,

Agradeço a Alessandro Pinzani (Prof. Dr. da UFSC) os comentários feitos sobre a divisão dos deveres jurídicos em Kant, lembrando a relação importante entre Kant e Ulpiano, bem como por ter me enviado seu excelente texto: Der systematische Stellenwert der pseudo-ulpianischen Regeln in Kants Rechtslehre, (In: Zeitschrift für philosophische Forschung. 59/1, 2005, 71-94).

2 Cfr. GOYARD-FABER, Simone. La Philosophie du Droit de Kant. Paris: Vrin, 1996, p.39.

MS Ak237. (Para as citações bibliográficas serão usadas as abreviaturas das iniciais das obras de Kant no original em alemão. A edição utilizada para este trabalho é: KANT, I. Werke in XII Bänden. Herausgegeben Von Wilhelm Weischedel. Frankfurt am Main: Suhrkamp, 1988).

$4 \mathrm{KpV}$ AK144 
apenas a própria ação conta, não a meta ou objetivo a ser atingido. Em resumo, se pretendemos uma ação moral, então não se trata apenas de agir conforme ao dever, por inclinação, ou qualquer outro mote; mas agir por dever. Entretanto, Kant não se detém apenas ao mundo moral. É sabido que a condição humana é terrena e, portanto, cotidianamente impulsionada por obrigações simples, desprovidas de caráter moral. É nesse campo que atua o caráter heterônomo, externo, e necessário, das leis jurídicas. E, enquanto lei, traz consigo, não apenas o dever, mas também a coação.

Quando nos ocupamos com a questão da coação, pensamos sempre nas condições de sua aplicabilidade, visto que não podemos esquecer que o homem vive em sociedade. Lembremos aqui que, de acordo com Kant, o que caracteriza a condição humana é sua insociável sociabilidade. Ou seja, Kant considera como conceito fundamental da filosofia da história, o fato da dificuldade encontrada pelos homens para viverem em sociedade. A sociedade, ao mesmo tempo que obriga os homens a se associarem, coloca-os em uma situação de conflito. Desse conflito, temos as ambigüidades, que apenas podem ser suportadas pela força da lei. A lei jurídica determina, sob força de coação, a convivência pacífica entre os homens. E é justamente aqui que vemos o lugar próprio do direito. Se, conforme falamos no início, direito e justiça se aproximam, então fica evidente que o direito, que deve fornecer as leis jurídicas de um Estado, necessita não se opor ao dever. Ora, o que podemos perceber, a partir disso, é que essa lei jurídica, que possibilita a vida em sociedade, não possui um caráter apenas meramente legal. Pelo contrário, faz-se necessária sua relação com as moralidades, pois, se a lei jurídica se afastar por completo da lei moral, a sociedade não cumpre seu principal papel, que é o de possibilitar a sociabilidade entre insociáveis. Há necessidade de mais uma aproximação entre os âmbitos da moralidade e da legalidade. A situação da insociabilidade entre os homens não é resolvida apenas sob força da coação jurídica, pois disso poderíamos ter uma sociedade de demônios, cumpridores das leis jurídicas, mas não necessariamente agindo moralmente. Cumprir a lei não implica, como mostramos com a citação acima, a moralidade. Não basta agirmos conforme o dever, mas por dever. E, se considerarmos que o fundamental papel do Estado é possibilitar a vida estável entre seus membros, favorecendo a sociabilidade, então faz-se necessária a intervenção de uma legalidade que possa cumprir também com os desafios da moralidade.

A grande questão que se impõe, a partir de tais considerações, refere-se à possibilidade de o Estado permitir que o interesse particular de cada homem se realize segundo uma regra que possa valer igualmente ao interesse de outros. Temos, com isso, a idéia de um pacto civil, indicada por Kant na quinta proposição da Idéia de uma história universal de um ponto de vista cosmopolita. A idéia de pacto ou de contrato, apresentada por Kant, encontra-se ligada àquelas de Locke, Hobbes e Rousseau. Ou seja, a partir das idéias propostas por esses filósofos, Kant formula uma discussão que busca superar os problemas apresentados 
por elas, dando ao conceito de contrato uma aproximação mais efetiva ao direito e àquilo que é justo. As análises sobre a teoria do contrato em Hobbes, por exemplo, levam Kant a mostrar que o filósofo deixa de lado importantes considerações sobre o assunto. Em primeiro lugar, Hobbes não distinguiria a execução do contrato do princípio de sua edificação. A seguir, a análise de Hobbes não abordaria diretamente a questão da especificidade do pacto de união civil em relação aos contratos ordinários; e, por último, Hobbes não falaria do problema da segurança necessária para a aceitação de uma promessa.

Apesar de todas as críticas kantianas endereçadas a Hobbes serem fundamentais para o desenvolvimento das idéias acerca do contrato, aquilo que nos importa é que, na origem do contrato social, podemos perceber como toda liberdade individual possui sempre a tendência a se expandir indefinidamente. Ora, desde logo, podemos notar que haverá um conflito inevitável entre essas liberdades individuais. E Kant busca, através das análises sobre as idéias de Hobbes e Rousseau, uma possível solução para o difícil problema do contrato social. Partindo do inevitável conflito entre as liberdades individuais, poderíamos dizer que nos restariam três possíveis soluções para o problema: Em primeiro lugar, poderíamos imaginar que cada indivíduo fosse para um lugar isolado, distante de todos os outros. Nesse caso, a liberdade permaneceria total, pois afastaríamos o conflito com o isolamento. Kant, no entanto, pergunta como poderíamos imaginar um progresso na humanidade a partir dessa idéia? Ou melhor, que tipo de humanidade poderíamos esperar de indivíduos isolados entre si? Esse indivíduo, que se afasta e se isola de todos os outros, é justamente o homem selvagem e bruto, descrito por Rousseau no Discurso sobre a origem da desigualdade entre os homens. Num segundo momento, Kant nos mostra que poderíamos supor um soberano déspota que suprimisse todas as liberdades individuais. Ou seja, a solução para o conflito estaria no sufocamento de qualquer liberdade individual. Nesse caso, a coação seria total, resultando no fim do estado de guerra entre as liberdades individuais. Entretanto, poderíamos pensar em progresso da humanidade em um Estado onde o essencial da humanidade está impedido de se manifestar? Em outras palavras: como imaginar uma sociedade onde a liberdade, pressuposto do caráter mais essencial do homem, é impedida de manifestar-se? Uma terceira solução seria imaginar um acordo justo entre as liberdades. Para tal fim, deveríamos imaginar uma reciprocidade justa na coação, pois sob leis é imprescindível a coação; entretanto, não podemos nos arriscar a voltar ao segundo momento, onde um soberano déspota impõe atos coercitivos desequilibrados. E é justamente aqui que reside o direito, pois o equilíbrio entre as coações é o papel mesmo do direito. Com isso, a meta final do direito se confundiria com aquela da humanidade. Vejamos como Kant defende a liberdade na quinta proposição da Idéia de uma história universal do ponto de vista cosmopolita: 
É unicamente na sociedade (e precisamente nela) que é permitida a maior liberdade e, por conseqüência, um antagonismo geral entre os seus membros; e que, no entanto, a sociedade determina e protege, da maneira mais estrita, os limites dessa liberdade para que ela se possa manter com a liberdade dos outros; visto que é somente nessa sociedade que o desígnio supremo da natureza, o desenvolvimento de todas as suas disposições na humanidade; pode ser atingido, por essa mesma razão a natureza quer também que a própria humanidade realize esse desígnio, como todos os fins do seu destino; por isso é necessário haver uma sociedade em que a liberdade, sujeita a leis externas, esteja ligada, no mais alto grau, a um poder irresistível, quer dizer, a uma constituição civil perfeitamente justa, que seja a tarefa suprema da natureza para a espécie humana. ${ }^{5}$

O modo como Kant nos apresenta a idéia de uma constituição civil justa, nos faz perceber que ele acredita na idéia de um progresso da humanidade expresso sob a idéia de uma sociedade justa. O direito, que dá forma a essa sociedade justa, tem como missão primeira a realização do acordo entre as liberdades individuais antagônicas. Não há constituição civil perfeitamente justa, se esse acordo não for perfeito, ou seja, os atos coercitivos devem, necessariamente, estar a serviço das liberdades individuais, sendo perfeitamente recíprocos. O equilíbrio das liberdades individuais será garantido por uma constituição, sem que seja necessária a fuga do homem do seio da sociedade e, muito menos, sem que seja necessária uma força coercitiva desigual que abafa a própria liberdade.

A principal característica do direito é a de indicar a coação como aquela que se impõe ao meu agir, impedindo que faça obstáculo à liberdade do outro. Em outros termos, a igualdade suposta no direito implica um obstáculo ao obstáculo, pois, para que, ao mesmo tempo que sou coagido, possa também coagir, é necessária uma reciprocidade eqüitativa. Podemos aqui lembrar o modelo tantas vezes seguido por Kant em suas Críticas, a saber, o modelo newtoniano, onde a cada ação corresponde uma reação, que assegura aos corpos celestes sua justa posição. É pressuposta, para o cumprimento do imperativo hipotético coercitivo do direito, uma igualdade. O equilíbrio entre o agente coercitivo e o agente coagido é necessário para o direito. Afirma Kant:

A lei de uma coação recíproca, que concorda necessariamente com a liberdade de todos, sob o princípio da liberdade universal, é em certo modo a construção daquele conceito; isto é, a exposição do mesmo em uma intuição pura a priori, seguindo a analogia da possibilidade dos movimentos livres dos corpos, sob a lei da igualdade da ação e reação. ${ }^{6}$

A coação é, então, pressuposta pelo direito. Ora, tal afirmação exposta claramente no §D da Introdução à Doutrina do Direito - Metafísica dos Costumes, suscita ainda muita discussão dos intérpretes da obra de Kant. Não são raros os co-

\footnotetext{
Idée. AK VIII 22.
}

MS AK232-233. 
mentadores que abrem capítulos especiais para responder à questão que se desenrola a partir de tal afirmação ${ }^{7}$, a saber: como o direito, enquanto direito à liberdade, pode ser pensado sem contradições com a coação? Podemos esboçar uma resposta, seguindo os passos dados por Höffe, na Introduction à la Philosophie Pratique de Kant, que não se afastam do que é colocado por Simone GoyardFabre, em La Philosophie du Droit de Kant. Segundo as análises de Höffe, o esclarecimento da questão acima descrita parte da necessidade de uma análise lógica. Dois são os princípios que devemos levar em conta para tal fim: o princípio de contradição e o princípio da dupla negação.

Em primeiro lugar, devemos lembrar que, para Kant, a negação da liberdade é a própria negação do justo. É necessário lembrar, também, que a coação pode ser considerada como uma negação da liberdade. "Todo o contrário ao direito (Unrecht) é um obstáculo à liberdade segundo leis universais: porém, uma coação é um obstáculo ou uma resistência à liberdade". ${ }^{8}$ Se considerarmos que um determinado uso da liberdade é não-justo, então a negação desse uso da liberdade será nãoinjusto. Assim, a coação que se exerce sobre essa liberdade pode ser considerada como não-injusta. Ora, isso equivale a dizer que a coação é justa. Kant utiliza, nessas premissas lógicas, o conceito de justo e injusto; o primeiro significa aquele ato que é juridicamente autorizado, enquanto o injusto é o ato juridicamente nãoautorizado ou proibido.

A aparente contradição entre coação e direito é desfeita, quando se percebe haver uma ligação analítica entre eles. E, aqui encontramos a proximidade acima aludida, com o texto de Goyard-Fabre, que afirma não haver oposição entre a coação e a liberdade; mas, pelo contrário, a coação faz um obstáculo a tudo aquilo que faz obstáculo à liberdade. Assim, está garantida sua coexistência, através da reciprocidade e de sua limitação. Com isso, afirma Goyard-Fabre, a liberdade está analiticamente contida no princípio universal do direito, e, portanto, possui validade a priori. Ora, se seguimos a linha de raciocínio que afirma haver uma ligação analítica entre direito e coação, então deixa de existir a contradição, visto que juízos analíticos não são constituídos por elementos que diferem entre si. A partir disso, pode-se dizer que direito e coação são a mesma coisa, que não há diferença, pois o conceito de coação se acha analiticamente compreendido no conceito de direito. Do mesmo modo que o princípio universal do direito acima descrito, a coação possui seu valor a priori. Se a lei da coação estiver de pleno acordo com o princípio de reciprocidade necessária para a liberdade, então é ela mesma uma construção. Diz Kant:

\footnotetext{
Entre outros, podemos citar: Höffe, O. Introduction à la Philosophie Pratique de Kant; Arendt, H. Juger: sur la philosophie politique de Kant. Paris: Seuil, 1991. Delbos, Victor, La Philosophie pratique de Kant. Paris: PUF, 1969. Goyard-Fabre, Simone. Kant et le problème du droit. Paris: Vrin, 1975. Shneewind, Jérome, L'Invention de l'Autonomie. Paris: Gallimard, 2001.

8 MS AK231.
} 
A lei de uma coação recíproca, que concorda necessariamente com a liberdade de todos, sob o princípio da liberdade universal, é, em certo modo, a construção daquele conceito; isto é, a exposição do mesmo em uma intuição pura a priori, seguindo a analogia da possibilidade dos movimentos livres dos corpos, sob a lei da igualdade da ação e reação. ${ }^{9}$

Certo é, então, que deve haver uma igualdade e uma reciprocidade na coação que permite a própria liberdade. Porém, pode-se perguntar mais profundamente por essa "tensão" entre "a coerção recíproca, a lei da igualdade da ação, de um lado, e, de outro, o princípio da liberdade universal". ${ }^{10}$

No âmbito da legalidade, a coação não é só legitima, ela também é necessária. Sem a coação, não há direito. Por isso, a possibilidade de equiparamos os conceitos a ponto de torná-los analíticos. Ora, retomando o que vimos acima, se o direito não pede nada além de uma conformidade externa, onde não se exige uma determinação fundada num ato de amor ao direito ou na moral, então o direito adquire seus móbeis do exterior. E, se os motivos da ação são oriundos do exterior, como eles agem de maneira a fazer o indivíduo cumprir a lei? A tensão maior não se encontra no campo conceitual que busca contrapor coerção e liberdade, mas na própria ação do sujeito. ${ }^{11}$ Se seguirmos passo a passo os capítulos iniciais da Metafísica dos Costumes, vemos que Kant procura fugir do possível conflito entre coação e liberdade, ao mostrar que o ato, que obriga a obediência ao direito, provém de um motivo exterior e não da própria consciência. E esse motivo exterior é a coação, cumprida a necessidade de um perfeito acordo entre ela e a lei da liberdade. Mais uma vez, lembramos aqui a necessidade da reciprocidade entre os atos coercitivos, pois a garantia de tal reciprocidade se acha fundada na liberdade individual exposta num plano coletivo.

Da universalidade da liberdade provém uma espécie de autorização de coação. Enquanto liberdade externa, a vontade jurídica suscita nos outros um poder de me coagir. Nesse nível de objetividade, a lei jurídica retira dessa autorização de

9 MS AK232. Sobre esse tema ver também outras passagens de Kant, principalmente em Teoria e Prática A240: "Em efeito, como todo direito consiste em limitar a liberdade de todos os demais à condição de que possa coexistir com a minha, segundo uma lei universal, e como o direito público (em uma comunidade) é meramente o estado de uma efetiva legislação, conforme com esse princípio e assistida por um poder, legislação em virtude da qual todos quantos pertencem a um povo com súditos se encontram, ao fim, em um estado jurídico (status iuridicus), a saber, o de igualdade de ação e reação entre arbítrios, que se limitam mutuamente conforme a lei universal da liberdade (o que se chama "estado civil"), segue-se daí que nesse estado o direito inato de cada um (vale dizer, previamente a toda ação jurídica por sua parte), em ordem à faculdade de coagir a todos os demais para que permaneçam sempre dentro dos limites de um uso de sua liberdade que esteja de acordo com a minha, é igual para todos sem exceção".

${ }^{10}$ Cf. TERRA, Ricardo. A Política Tensa. São Paulo: Iluminuras, 1995, p. 82.

11 Ricardo Terra soube muito bem perceber a amplitude da tensão no ato do indivíduo ao tratar da questão da autonomia como conceito possibilitador da compreensão da tensão conceitual entre coação e liberdade. A autonomia, ou o ato de o próprio sujeito dar a si mesmo as leis, é determinante para se visualizar a garantia de realização dos fins jurídico-políticos sem conflitos com a finalidade ético-moral. 
coação sua própria normatividade, no sentido de transformar o ato livre de autorização em uma obrigação que sanciona a coação. Por isso a reciprocidade requerida pelo ato coercitivo se traduz no ato de submissão necessário, onde cada um exige simultaneamente do outro o mesmo. Vimos, acima, como Kant afirma que direito é liberdade. Entretanto, não podemos esquecer que aqui tratamos de liberdade no sentido de ser limitada pela presença da liberdade de outros. E esse conceito de liberdade se faz fundamental no âmbito do jurídico. Se a liberdade não encontrasse seu próprio limite nela mesma, ou seja, se a presença de outra liberdade não fosse o fundamento para a liberdade, então o homem seria um ser acabado e, portanto, também determinado. O fato de ser um ser livre e, ao mesmo tempo, limitado pela minha liberdade, torna possível o caminho do esclarecimento. A coação, ao se fazer junto com a liberdade, proporciona a possibilidade de desenvolvimento e progresso. Porque somos livres para transgredir e invadir a liberdade do outro, caso no qual a liberdade se transforma numa não-liberdade para o outro, há o desafio do obstáculo. Tal como a negação da negação, é necessário um obstáculo ao obstáculo. Ora, esse jogo de forças dá à coação uma função estrutural, ou seja, ela restaura como força justa a liberdade que sofre a ameaça de ser negada pelo obstáculo surgido. Daqui a definição de direito dada por Kant, sem a necessidade de se recorrer à experiência da lei estabelecida. Tal definição, fundada na liberdade e na coação, é um "dever-ser".

A finalidade política do homem em Kant é viver numa sociedade justa. Para tanto, é necessária a postulação de um estado de direito, onde a eqüidade seja atingida, apesar da oposição natural dos indivíduos ao estado de sociabilidade. Esse estado de direito é, para Kant, o estado da liberdade. Sua finalidade é permitir que cada um de seus membros possa conviver da maneira mais harmoniosa possível com os outros, afastando o máximo possível a intromissão em sua vida particular. O estado de direito postulado por Kant se afasta radicalmente daquele Estado despótico e, sobretudo, do Estado paternalista, que busca a felicidade de seus membros, sem levar em consideração, na maior parte das vezes, sua consciência moral e política. Por isso, a necessidade das leis jurídicas, que emprestam ao Estado a garantia de estabilidade e de igualdade, na reunião da multiplicidade de homens. O direito será, assim, o fundamento dessa sociedade justa. A finalidade política somente será atingida, quando a sociedade estabelecer suas leis jurídicas de maneira a respeitar a liberdade de cada indivíduo. As disposições morais devem permanecer como orientadoras da ação, mas agora suportadas também pela lei jurídica. As máximas determinantes da minha vontade servem como leis universais morais, mas também como fundamento das leis que dirigirão a sociedade justa.

Fundar o direito na liberdade e na coação é mostrar sua reciprocidade com o conceito de justiça. A partir de agora torna-se mais clara a afirmação inicial de nosso texto, onde mostramos que, segundo Kant, podemos entender quase como sinônimos os conceitos de direito e justiça. E podemos compreendê-los assim, 
porque a liberdade e a coação nos indicam o papel do dever nessa relação. Toda lei traz um ato coercitivo consigo, esteja ele designado como imperativo ou como coação. O que importa é que não há lei sem dever, do mesmo modo que não há justiça sem dever. O conceito de dever é ponto comum entre os âmbitos da moralidade e da legalidade. Assim, poderíamos re-afirmar que o dever moral, trazido à luz pelo imperativo categórico, é representado, no âmbito da legalidade, pelo direito e pela justiça.

\section{Referências}

ARENDT, Hanna. Juger: sur la philosophie politique de Kant. Paris: Seuil, 1991.

CRAMPE-CASNABET, Michèle. Le gouvernement de la raison - Kant. Paris: Bordas, 2004.

DELBOS, Victor, La Philosophie pratique de Kant. Paris: PUF, 1969.

GOYARD-FABRE, Simone. Kant et le problème du droit. Paris: Vrin, 1975.

. La Philosophie du droit de Kant. Paris: Vrin, 1996.

HÖFFE, O. Introduction à la Philosophie Pratique de Kant. Paris: Vrin, 1993.

KANT, Immanuel. Crítica da Razão Prática. Trad. Valério Rohden. São Paulo: Martins Fontes, 2003.

1999 1999 Idéia de uma história universal do ponto de vista cosmopolítico. Lisboa: Didáctica Editora, La Metafísica de las Costumbres. Trad. Adela Cortina y Jesús Conill Sancho. Madrid: Tecnos, nos, 1986 Teoría y Práctica. Trad. Juan Palácios; M. Francisco López y Roberto Aramayo. Madrid: Tec-

Werke in XII Bänden. Herausgegeben Von Wilhelm Weischedel. Frankfurt am Main: Suhrkamp, 1988.

SHNEEWIND, Jérome, L'Invention de l'Autonomie. Paris: Gallimard, 2001.

TERRA, Ricardo. A Política Tensa. São Paulo: Iluminuras, 1995.

TOSEL, André. Kant révolutionnaire. Droit et politique. Paris: PUF, 1990. 